Territorios 36 / Bogotá, 2017, pp. 23-46

ISSN: 0123-8418

ISSNe: $2215-7484$

Ciudades y conflictos en América Latina: ayer, hoy y mañana (I)

\title{
La desigualdad invisible: el uso cotidiano de los espacios públicos en la Lima del siglo XXI*
}

Invisible Inequality: 'Public Spaces' Everyday Life in the 21st Century's Lima

A desigualdade invisivel: o uso cotidiano dos espaços públicos em Lima do século XXI

Pablo Vega Centeno**

Recibido: 10 de junio de 2016

Aprobado: 12 de septiembre de 2016

Doi: http://dx.doi.org/10.12804/revistas.urosario.edu.co/territorios/a.5097

Para citar este artículo:

Vega Centeno, P. (2017). La desigualdad invisible: el uso cotidiano de los espacios públicos en la Lima del siglo XXI. Territorios (36), 23-46. Doi: http://dx.doi.org/10.12804/revistas.urosario.edu.co/territorios/a.5097

* Este artículo forma parte del marco del estudio sobre la densificación de Lima que el Centro de Investigación de la Arquitectura y la Ciudad (CIAC) de la Pontificia Universidad Católica del Perú (PUCP) viene llevando a cabo con apoyo financiero de la Dirección de Gestión de la Investigación de la PUCP.

** El autor es sociólogo con doctorado en arquitectura en la Universidad Católica de Lovaina. Actualmente es miembro del CIAC-PUCP $y$ docente del Departamento de Arquitectura de la Pontificia Universidad Católica del Perú. Correo electrónico: pvega@pucp.edu.pe. ORCID: http://orcid. org/0000-0002-0880-3196 
Palabras clave

transeúnte, espacio público, Lima, vida cotidiana, conflictos urbanos, desigualdad.

Keywords passerby, public space, Lima, everyday life, urban conflicts, inequality.

Palavras-chave

transeunte, espaço público, Lima, vida cotidiana, conflitos urbanos, desigualdade.

\section{RESUMEN}

El proceso de transformación que experimenta Lima en la actual era de la globalización ha supuesto la agudización de prácticas de segregación y/o exclusión en la forma de usar los espacios públicos de la ciudad aunque, paradójicamente, éste no parece ser un problema que preocupe a los limeños. El objetivo de este artículo es sustentar que la vida cotidiana en los espacios públicos expresa las grandes desigualdades sociales que existen en Lima, las cuales ofrecen múltiples facetas en conflicto, como la del conductor de vehículo motorizado con el habitante-transeúnte o la del habitante-residente con el habitante-transeúnte, las que se suelen superponer a desigualdades más visibles como el nivel de ingreso o el lugar de residencia.

\section{AbSTRACT}

The transformation process experienced by Lima in the current era of globalization has led to the intensification of segregation and/or exclusion practices on how to use urban public spaces, although paradoxically, this does not seem to be an issue that preoccupies Lima citizens. The aim of this work is to sustain that everyday life in public spaces expresses the big social inequalities that exist in Lima, which offer multiple sides in conflict, for instance the passerby against motor vehicle driver or the inhabitant-resident against inhabitant-passerby, which often overlap more visible inequalities such as the level of income or place of residence.

\section{Resumo}

O processo de transformação que experimenta Lima na atual era da globalização tem suposto a aguçadora de práticas de segregação e/ou exclusão na forma de usar os espaços públicos da cidade ainda que paradoxalmente este não parece ser um problema que preocupe aos limenhos. O objetivo deste artigo é sustentar que a vida cotidiana nos espaços públicos expressa as grandes desigualdades sociais que existem em Lima, as quais oferecem múltiplas facetas em conflito, como a do condutor de veículo motorizado com o habitante-transeunte ou a do habitante-residente com o habitante-transeunte, as que se costumam superpor a desigualdades mais visíveis como o nível de ingresso ou o lugar de residência. 


\section{Introducción}

Lima es una metrópoli emergente en el contexto de las reestructuraciones que vienen ocurriendo en las grandes ciudades de América Latina, con motivo de las dinámicas económicas globales que tienen al inversor inmobiliario como uno de sus principales agentes. Gracias a la estabilidad de los indicadores macroeconómicos del país, la ciudad se viene convirtiendo en un destino atractivo para la localización de inversiones que buscan hacer negocios principalmente en torno a la explotación de recursos minerales y energéticos. Por otra parte, esta bonanza económica va de la mano con el aumento de empleo precario contratado por empresas formales o generado de manera informal como estrategia de supervivencia, fenómeno que fuera estudiado por Sassen (1991) a escala global.

Estos cambios ocurren en el marco de una urbe donde ya existían numerosos conflictos urbanos, signados principalmente por la desigualdad social de oportunidades entre sus habitantes. Y es que los cambios que engendra la globalización se han superpuesto a una ciudad que ya estaba caracterizada por las grandes diferencias existentes entre las zonas de urbanización regular y las numerosas ocupaciones irregulares que ocupan arenales desérticos o las faldas de los cerros que circundan el continuo urbano y que llegan a representar aproximadamente un tercio del área ocupada por la metrópoli. Sobre este escenario de exclusiones, la globalización agrega una nueva forma de marginación, sustentada en la generación de nodos urbanos, articulados a la red vial y a los flujos globales de información y comunicación, pero relativamente aislados del continuo urbano.

En este contexto Lima comienza, además, a experimentar una mayor densidad del espacio construido, donde se multiplican las inversiones en edificaciones de mayor altura tanto en las zonas regularmente habilitadas como también en aquellas que surgieron por invasiones de terreno. Como resultado, a los conflictos derivados por las condiciones de exclusión social que viven los barrios populares de origen irregular se fueron agravando otros que son sensibles a la percepción ciudadana como la violencia urbana expresada en delincuencia, la congestión vial, la acumulación de basura o el aumento de la contaminación ambiental, tal como lo registra una encuesta de opinión realizada en agosto de 2015 por el observatorio ciudadano Lima Cómo Vamos $^{1}$. A ello debemos agregar el desigual acceso a las oportunidades laborales, pues la estructura urbana de la ciudad tiende a concentrar su principal oferta de empleo en el área central, haciendo inevitable que mucha población, principalmente de bajos ingresos, tenga que realizar viajes extensos y en medios de transporte público de baja calidad por motivos laborales (Gonzales \& Del Pozo, 2012; Vega Centeno, Dextre \& Alegre, 2011)

Existe, no obstante, una dimensión de los problemas de la ciudad que es apenas percibida por la población y la opinión pública en general y es la referida a la baja calidad de los espacios públicos de la
${ }^{1}$ De acuerdo a la encuesta aplicada por Lima Cómo Vamos, el $85 \%$ de entrevistados identifica a la delincuencia y la inseguridad ciudadana como uno de los principales problemas de $\mathrm{Li}$ ma, mientrasel $49 \%$ señala al transporte público y un $35 \%$ a la acumulación de basura y falta de limpieza pública. En cambio, apenas el $5 \%$ alude como problema a la baja calidad de los espaciospúblicos (Lima Cómo Vamos, 2015, p. 5).

territarias 36

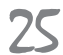


ciudad a la cual aluden apenas el $5 \%$ de los entrevistados en la encuesta antes mencionada. Por otra parte, los estudiosos de lo urbano han concentrado su atención a los problemas y conflictos urbanos generados por la tenencia del suelo, el derecho a la vivienda o las condiciones de exclusión que experimentan los barrios marginales comprendidos bajo la mirada de una ciudad popular. El espacio público parece aludir a un problema de segundo orden, referido probablemente más a las opciones recreativas de los habitantes que a una necesidad urgente de inclusión social como experiencia urbana.

El objetivo del presente artículo es proponer una lectura del proceso actual de transformación de Lima haciendo visible la condición de espacio social de los espacios públicos de la ciudad. Nuestra hipótesis de trabajo es que la vida cotidiana que ocurre en los espacios públicos expresa las desigualdades que se traducen, entre otros aspectos, en los privilegios que conductores de vehículos y residentes de urbanizaciones tienen sobre los peatones, que tienden a ser ignorados o marginados por la gestión urbana de las municipalidades.

Desde esta perspectiva será necesario, en primer lugar, precisar cómo entendemos la noción de espacio público y luego aplicarla en el análisis del proceso urbano de Lima. En un segundo momento analizaremos las relaciones entre conductores y peatones así como entre residentes o vecinos y transeúntes, considerando los diferentes actores involucrados. Para ello partiremos de la información recogida en diversos estudios empíricos sobre el particular y nuestras propias notas de observación de campo.

\section{Definiendo al espacio público urbano}

La noción de espacio público ha sido utilizada en la temática urbana originalmente como una referencia urbanística a la composición del tejido de una ciudad, donde diferenciamos espacios privados, usualmente cerrados de aquellos donde existe el libre acceso y tránsito de los habitantes de la ciudad (Panerai \& Mangin, 2002). Como resultado, las representaciones del espacio público se asocian a formas espaciales, que pueden aludir a bordes, como a nodos o vías; del mismo modo, podemos identificar los tamaños de superficies que ocupan en el conjunto de la ciudad. Pero, como recuerda Borja, "el espacio público moderno resulta de la separación formal (legal) entre la propiedad privada urbana y la propiedad pública" (2003, p. 122), que supone que este suelo libre de construcción es destinado al uso comunitario o a equipamientos colectivos de interés general.

Es habitual, por ello, referirnos como espacios públicos a aquellos espacios de acceso común con una forma particular como son plazas, calles o parques (Kostof, 2000), donde el colectivo humano que habita una ciudad tiene libre acceso - sin importar cuando ni quien-, libertad de acción - no necesariamente explícita ni determinada- y libertad a permanecer inactivo (Remy \& Voyé, 1981; Kostof, 
2000). Esta definición, como señalan Duhau \& Giglia (2008), constituye una suerte de tipo ideal que busca conjugar enfoques de la filosofía política con la teoría social.

Los espacios públicos como componentes fundamentales de la ciudad y su libre acceso como un derecho ciudadano forman parte de un campo de discusión relativamente nuevo en el estudio sobre lo urbano en el Perú. Las discusiones en torno al derecho a la ciudad durante el siglo XX han estado centradas en la vivienda, la consolidación de los barrios populares o la participación en los gobiernos locales (Calderón, 1990; ídem, 2014).

La introducción de la noción de espacio público al estudio de la cuestión urbana en el país en parte es el resultado de la difusión de enfoques teóricos como los propuestos por Borja (2003) o Delgado $(1999 ; 2007)$, la propia noción de esfera pública para la sociedad moderna de Habermas (1991) así como la acogida que tuvo el trabajo de Takano \& Toke-shi (2007), uno de los primeros estudios publicados sobre el espacio público en Lima junto con el de Chion \& Ludeña (2005) o los ensayos de Vega Centeno (2004; 2006). Borja pone en evidencia la dimensión política del espacio público como escenario potencial de afirmación ciudadana en que muchas veces se expresa o manifiestan cuestionamientos al orden social existente, que ha sido fermento de importantes hechos revolucionarios a través de la historia y, por ende, es un espacio que busca ser controlado por aquellos que detentan el poder en una sociedad determinada.
En este contexto, autores como Caldeira (2007) resaltan la potencialidad del espacio público como espacio en el cual se expresa la igualdad y la participación ciudadana. Por su parte, Delgado (2007) se cuestiona en qué medida el espacio público, como espacio de socialización, permite el desarrollo de prácticas cotidianas donde el habitante de grandes ciudades aprende a vivir entre multitudes, reconociendo una condición de igualdad en situaciones de anonimato, que el autor define como una suerte de "derecho a la indiferencia" (p. 182). Delgado desarrolla este análisis en base al clásico trabajo de Simmel (1998) de principios del siglo XX que alude a una particular forma de practicar la ciudad que experimenta el habitante de grandes ciudades, principalmente en su condición de transeúnte, dimensión que fuera trabajada más adelante por Joseph (1988) y al que nos hemos referido en otro trabajo (Vega Centeno, 2006).

Estas aproximaciones al espacio público tienen como novedad el hecho de que surgen en el marco del proceso de globalización, suerte de tercera revolución urbana de la modernidad (Ascher, 2004), que tiende a vaciar de contenido los espacios urbanos para priorizar nodos urbanos en un territorio dominado por el espacio de los flujos (Castells, 1997). Al respecto Sassen $(1991 ; 2007)$ ya advierte sobre la tendencia a ignorar la condición de lugar de las ciudades globales y en esa perspectiva Borja (2003) propone entender al espacio público como el espacio donde se realiza la síntesis entre lugares y flujos. territarias 36 
En nuestro caso, interesa partir de un enfoque socio espacial, en la perspectiva propuesta por Lefebvre, donde interactúan tres dimensiones o aproximaciones conceptuales al espacio, las cuales nos refieren al espacio concebido o de la producción de la ciudad, al practicado o de los usos cotidianos y al vivido o de las representaciones (2013, pp.97-98). En otras palabras, aproximarse a los actores que participan directamente en la producción del espacio urbano, a la forma en que los habitantes se apropian cotidianamente de este y, finalmente, a los imaginarios que estos últimos producen de su propia experiencia urbana. Como señala Lefebvre, se trata de una triada conceptual donde interesa la interacción dialéctica entre las tres dimensiones propuestas. Consideraremos también el aporte de Salcedo (2002) quien advierte del peligro de construir una imagen idealizada del espacio público urbano, por lo que propone entender al espacio público como campo de lucha y prestar atención a su historicidad. En la misma línea, Carrión reclama entender al espacio público por su condición urbana - atendiendo a su rol en la ciudad-y su cualidad histórica (2007, p.81). En esta perspectiva, resulta pertinente la afirmación de Duhau \& Giglia, quienes afirman que el tipo ideal de espacio público democratizado solo se habría plasmado en muy pocos casos como Buenos Aires, México o São Paulo, donde sí existió una clase media y una clase obrera con sueldos relativamente elevados $(2008$, p. 50), que no fue el caso de Lima.
El debate surgido en torno a la condición del espacio público urbano en la ciudad de Lima ha sido saludable en la medida que se busca superar una mirada restringida a las cuestiones morfológicas, pero también corre el riesgo de confundir proyectos o aspiraciones políticas con las condiciones objetivas en que el espacio público urbano se constituye actualmente como espacio social.

Es por estos motivos que es importante examinar, atendiendo a la historicidad de los fenómenos, lo que ha venido ocurriendo con los espacios públicos en Lima. Para ello buscaremos centrarnos en el proceso urbano que experimenta la ciudad desde fines del siglo XX pero poniéndolo en relación con fenómenos que ocurrieron desde mediados de dicho siglo.

\section{La expansión urbana de Lima y su inserción en la economía global}

En términos morfológicos, la ciudad de Lima mantuvo durante cerca de tres siglos un tejido urbano en el que predominó la cuadrícula donde morfológicamente el espacio público lo constituyen las calles y la Plaza Mayor y el borde urbano estaba demarcado por la muralla que fue habilitada en la segunda mitad del siglo XVII. En estos espacios se encontraban cotidianamente los diversos habitantes de Lima, aunque en contextos donde la posición social de cada uno era reafirmada en criterios culturales y raciales. Estamos, pues, muy lejos de la concepción moderna de espacio público que citáramos en un inicio. 
Cuando en 1870 las murallas de la ciudad fueron demolidas, el Plan de Meiggs orientó la expansión de la ciudad mediante vías urbanizadoras que conectaban la ciudad con los antiguos balnearios localizados en los pueblos de Miraflores, Barranco y Chorrillos, proceso que continuó las décadas siguientes. Por otra parte, se habilitó la Plaza San Martín con motivo del centenario de la independencia y se urbanizaron terrenos colindantes en lo que es el actual distrito de La Victoria. Asimismo, a finales del siglo XIX, se inauguró el Parque de la Exposición como paseo destinado a la recreación de la aristocracia limeña y, en las primeras décadas del siglo XX, se construyó el Parque de la Reserva, en honor al reservista del ejército peruano. El conjunto de obras urbanas referidas fueron a su vez innovaciones importantes en la forma urbana de la ciudad, donde el espacio público como espacio social pasa a ser entendido como espacio de circulación, espacio cívico o de recreación de una clase dominante (Vega Centeno, 2013). El centro urbano y sus espacios públicos son, entonces, expresión de un poder dominante, como lo fue para la república aristocrática a finales del siglo XIX y la "patria nueva" de Leguía en las primeras décadas del siglo XX (Ludeña, 2002).

Hacia mediados del siglo XX dos procesos urbanizadores transformaron radicalmente la forma y la imagen de la ciudad. Por una parte, sociedades inmobiliarias que vinieron formándose desde inicios del siglo XX desarrollan proyectos de urbanizaciones residenciales, donde se prioriza el acceso vehicular y se diseñan parques interiores como áreas recreativas destinadas principalmente a sus futuros habitantes residentes; inclusive, en la década de los 60 se ofrecen las primeras urbanizaciones residenciales con acceso de carácter exclusivo para una población de alta renta, primer antecedente del concepto de condominio en Lima. Fue el caso de Las Casuarinas que, además, dividió el cerro en que se ubicaba, diferenciando la urbanización exclusiva de las barriadas formadas por invasiones de terreno a través del llamado "muro de la vergüenza” (Boano \& Desmaison, 2016).

Por otra parte, ocurren las grandes ocupaciones de terrenos por medio de invasiones en áreas periféricas de Lima de valor urbano de carácter residual, donde el objetivo principal de sus habitantes era dar una solución a su falta de acceso a vivienda en la ciudad. En términos espaciales es durante el siglo XX que el área de Lima se expande notablemente inclusive en forma más acelerada que su propio crecimiento demográfico, que también fue de carácter explosivo debido principalmente a grandes corrientes de migración interna ocurridas sobre todo entre 1940 y 1990.

El resultado fue una urbe que por primera vez alcanza una escala metropolitana, tanto en términos demográficos como espaciales, pero donde la densidad de ocupación es baja. La bibliografía sobre este proceso urbano es numerosa, pero son pocos los casos donde se presta atención a la forma en que se ha venido configurando el espacio público dentro de este nuevo tejido urbano. El principal foco de territarias 36

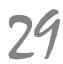


atención fue la habilitación de viviendas, tanto para sectores medios y altos, como la que producen las poblaciones de bajos ingresos.

Entre las pocas referencias, aunque indirectas, sobre el tratamiento de los espacios públicos urbanos podemos mencionar la proyección de la expansión de la urbe planteada por el Esquema director del Plan de Desarrollo Metropolitano Lima-Callao 1967-1980 (ONPU, 1967). Este plan, con influencia del movimiento de arquitectura moderna mundialmente liderado por Le Corbusier (1959), se preocupa por prever los espacios recreativos de la ciudad para las futuras décadas, definiendo un conjunto de grandes parques zonales en las áreas de expansión. Asimismo, se interesa por la conectividad de una serie de sub-centros urbanos proyectados, entendiendo las calles y avenidas como redes viales ante todo antes que como espacios públicos.

En suma, Lima a inicios de la década de 1980 era una ciudad de gran extensión aunque de baja densidad poblacional, donde la calle es tratada en los planes de desarrollo principalmente como vía antes que como espacio público - aunque se mantenga el diseño de veredas en toda la trama urbana pensando en un peatón que es tratado como "transporte no motorizado"-, situación que se hace más evidente en las urbanizaciones residenciales producidas entre 1950 y 1990. El abastecimiento de estas urbanizaciones tiende a concentrarse en sub-centros que albergan supermercados y otros comercios en una pequeña trama de calles definidas como zona comercial y de servicios. En cambio, el parque es entendido como área recreativa asociada a los residentes que circundan el espacio público, por una parte en las urbanizaciones residenciales y por otra en los grandes parques zonales, destinados al disfrute de aquellos que ocupan áreas de expansión de la ciudad.

La década de 1980 supone también un periodo de crisis tanto económica como política: un modelo de crecimiento sustentado tímidamente en la industria sustitutiva de importaciones es desmantelado, a la par que surgen grupos terroristas que producirán graves atentados en las ciudades del país entre 1980 y 1992 , haciendo explotar varios coches bomba en las calles de la ciudad. Una respuesta de la población fue levantar barreras o rejas de control en los accesos de varias urbanizaciones de clase media hacia el sureste de la ciudad. Del mismo modo, embajadas o canales de televisión construyeron muros de protección.

A principios de 1990, la política de ajuste estructural marcó el inicio de una política estable de corte liberal en la economía del país que coincide con la caída de los principales líderes de los grupos terroristas. Esto va a permitir importantes "cambios de piel" en la ciudad, como señala Ludeña (2002), los que expresan el retorno de la inversión inmobiliaria, a la par del aprovechamiento de nuevas tecnologías para la construcción y la comunicación. Estas iniciativas inmobiliarias se apoyan en la aún persistente sensación de miedo generalizado que en parte produjo el terrorismo en 
Lima, para legitimar una cierta aversión a la calle como espacio para la vida social. En una economía que comienza a ser estable, estos proyectos ofrecen espacios residenciales fortificados, protegidos de la calle, bajo el concepto de "condominio", así sea una gran urbanización o un nuevo edificio residencial, y lo hacen a través de diseños similares a los utilizados en grandes ciudades, con lo que además garantizan una suerte de acceso a la vivienda moderna. En suma, se trata de productos inmobiliarios que se ofrecen de manera sistemática en las grandes ciudades latinoamericanas en el proceso de reestructuración económica que vienen experimentando (De Mattos, 2008), afirmando la homogeneidad como un símbolo de estatus y de conexión global (Castells, 1997).

\section{Espacio social y relecturas del espacio público en las décadas recientes}

En términos de la composición del espacio público como forma urbana, la nueva inversión inmobiliaria aporta novedades en los productos que ofrece, al igual que en otras ciudades de América Latina (De Mattos, 2008). Por una parte, surge la oferta de grandes centros comerciales o malls cuya característica morfológica es la de tener una mayor independencia del tejido urbano, proponiendo el diseño de calles y hasta plazas artificiales dentro de su estructura. El desarrollo de la llamada industria del retail ha sido uno de los hitos más representativos de la inversión inmobiliaria en Lima, que se implementa no solamente en el área central de la metrópoli, sino que se localizan en áreas de expansión, convirtiéndose en íconos del progreso económico de una suerte de "ciudad emergente".

El enorme éxito y acogida que han tenido estos emprendimientos privados ha llevado a afirmar que grandes malls como el Mega Plaza o Plaza Lima Norte en la zona norte de la ciudad se han constituido como los grandes símbolos de una suerte de éxito de emprendimiento de una Lima emergente (Arellano, 2010), erigiéndose como los grandes espacios públicos para la población de áreas de expansión urbana. Si bien en un trabajo anterior hemos cuestionado la condición de espacio público de los grandes centros comerciales en tanto son propiedad privada y su diseño se organiza en función del consumo (Vega Centeno, 2006), no cabe duda que la iniciativa de la población puede estar generando procesos de apropiación y re-significación relativamente autónomos del espacio producido, fenómeno que merece ser estudiado con mayor atención. Por otra parte, existen diferencias formales en las inserciones de estas inversiones privadas en la ciudad que también merecen ser estudiadas con mayor detenimiento.

De otro lado, los espacios residenciales que se vienen produciendo ya no son urbanizaciones integradas al continuo urbano consolidado de la metrópoli, sino que se ofrecen bajo la modalidad de condominio, es decir, independizados del tejido urbano mediante muros ciegos. Esta oferta tiene territarias 36 
variaciones, pues puede ofrecer viviendas destinadas a población de ingresos altos como también edificios residenciales dirigidos a poblaciones de niveles de ingreso inferiores; inclusive, edificios independientes se ofrecerán como condominios siempre y cuando su diseño garantice accesos totalmente controlados.

Este modelo encarna una nueva propuesta de urbanización que se sustenta en parte en el crecimiento vertical de la ciudad, pero donde se privilegia una oferta de vida urbana que conecte hogares con servicios aglomerados en grandes equipamientos comerciales. En este estilo de vida propuesto, el espacio público desaparece completamente en una vialidad en que se reducen o se eliminan las aceras y los parques públicos se circunscriben a áreas recreativas o de ornato; inclusive, los parques zonales son reconvertidos en clubes, como actualmente los denomina el servicio de parques y jardines de la gestión metropolitana que entrara en funciones en enero de 2015. Asimismo, se han desarrollado importantes inversiones privadas en las playas del sur de la ciudad, produciendo condominios residenciales que se apropian casi en forma exclusiva de los accesos a las playas, privatizado un bien público como la playa, originalmente previsto al servicio de todos los ciudadanos. Esta sub-urbanización del litoral sur de Lima, como señala Ludeña, ha sido llevada a cabo como producto de una enorme especulación inmobiliaria con absoluta irresponsabilidad ecológica (2011, p. 85).
En la actualidad, el inversor inmobiliario se ha consolidado como el gran gestor de las principales transformaciones que viene experimentando la metrópoli. Por ejemplo, entre 2008 y 2012 se produjo un aumento espectacular del valor del metro cuadrado en la ciudad, merced del gran crecimiento de edificaciones en altura, y casi todo el suelo urbano al menos duplicó su valor, mientras en algunas zonas del área central el incremento fue diez o más veces superior (figura 1). Ahora bien, el estilo de vida que proponen estos nuevos edificios residenciales llevó a replantear el rol que los espacios públicos adquirirán durante el siglo XXI, en la medida que proponen áreas de reunión social, de juegos infantiles e inclusive gimnasios y piscinas.

Este tipo de oferta residencial incide en destacar que la calidad de vida se encuentra dentro de la vivienda y la presencia del vehículo al exterior es una invitación a conectar la vida cotidiana con espacios alejados del hogar. La calle se vuelve sinónimo de inseguridad y desaparece como escenario de vida para convertirse exclusivamente en vía de circulación. Llama la atención que este tipo de propuesta se ofrezca inclusive en zonas localizadas a proximidad de equipamientos y servicios atractivos a la vida diaria, pues siempre se evita invitar al cliente a caminar por los entornos del edificio residencial (figura 2).

Como resultado, podemos afirmar que el modelo de urbanización que sigue Lima en la actualidad tiende a centrar su comprensión del espacio público al de áreas verdes, sean recreativas o de ornato, donde 
Figura 1: Incremento del precio de departamentos en Lima: 2008-2012

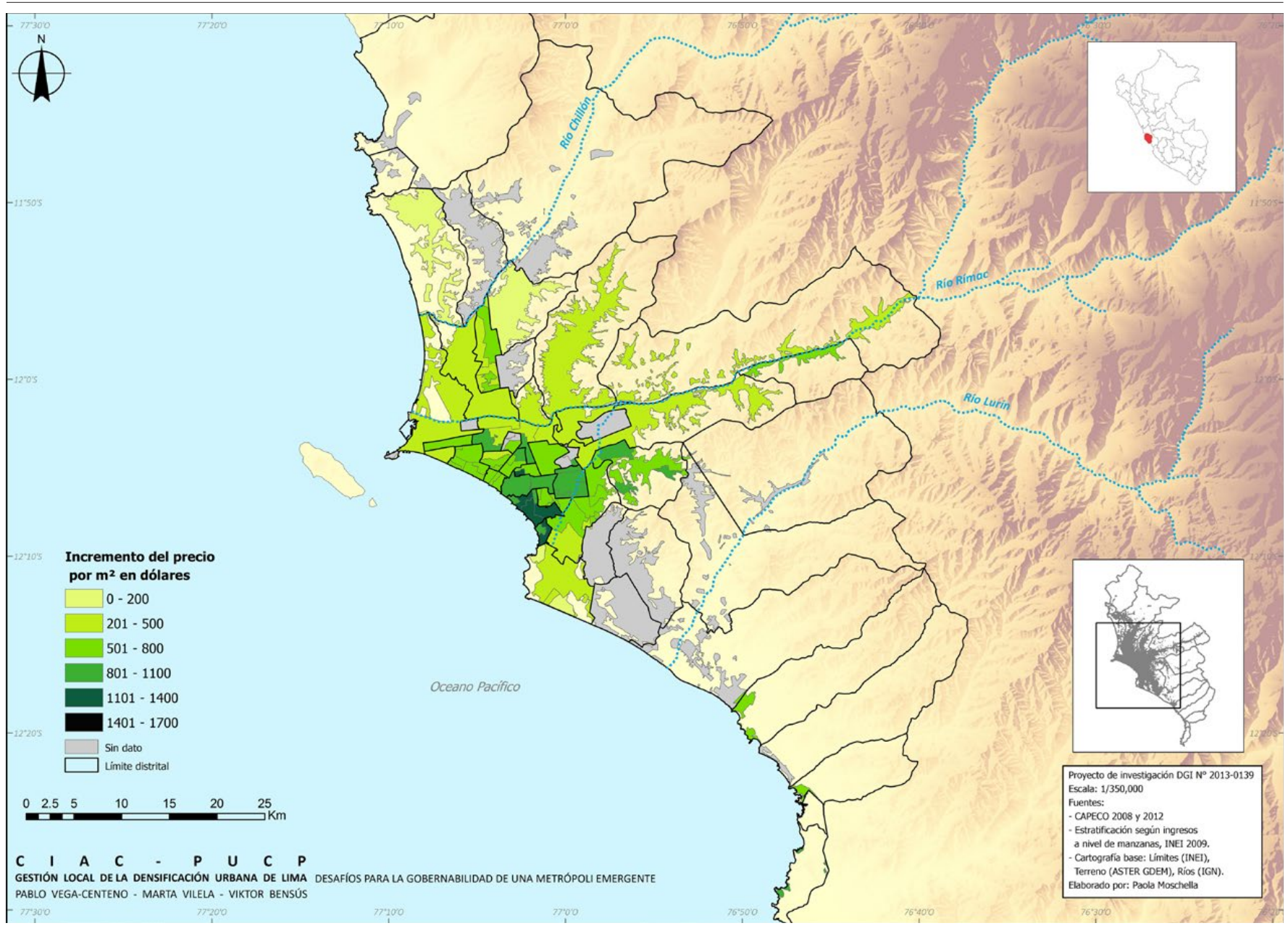

Fuente: CIAC-PUCP.

el entramado de redes viales tiene por único fin la conectividad de los ciudadanos mediante los medios de transporte que tengan disponibles o les sean accesibles. El vínculo de la residencia con el área verde tiende a construirse sobre criterios de paisaje antes

que de uso donde, además, esta propuesta es ofrecida como un símbolo de distinción social (figura 3 ).

Sin embargo, no podemos afirmar que el modelo actual sea una transformación del proceso urbano que Lima venía territarias 36 
Figura 2: Propaganda de vivienda en departamento en Jesús María, distrito del área central de Lima

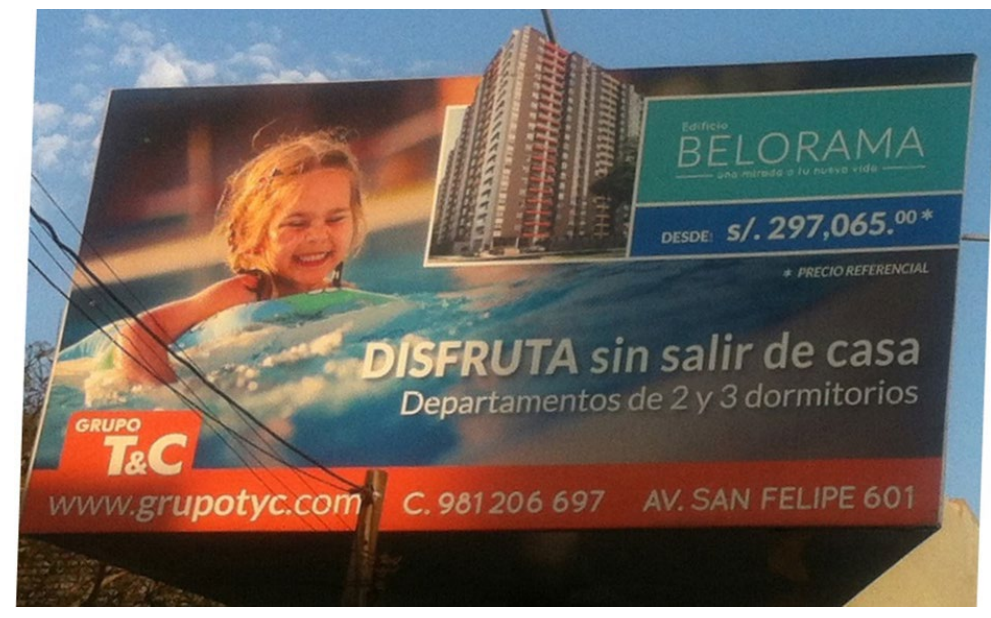

Fuente: Fotografía de Sandro Munari, 2015

Figura 3: Propaganda de vivienda en edificio en Surco, distrito ubicado dentro del área centro-este de Lima

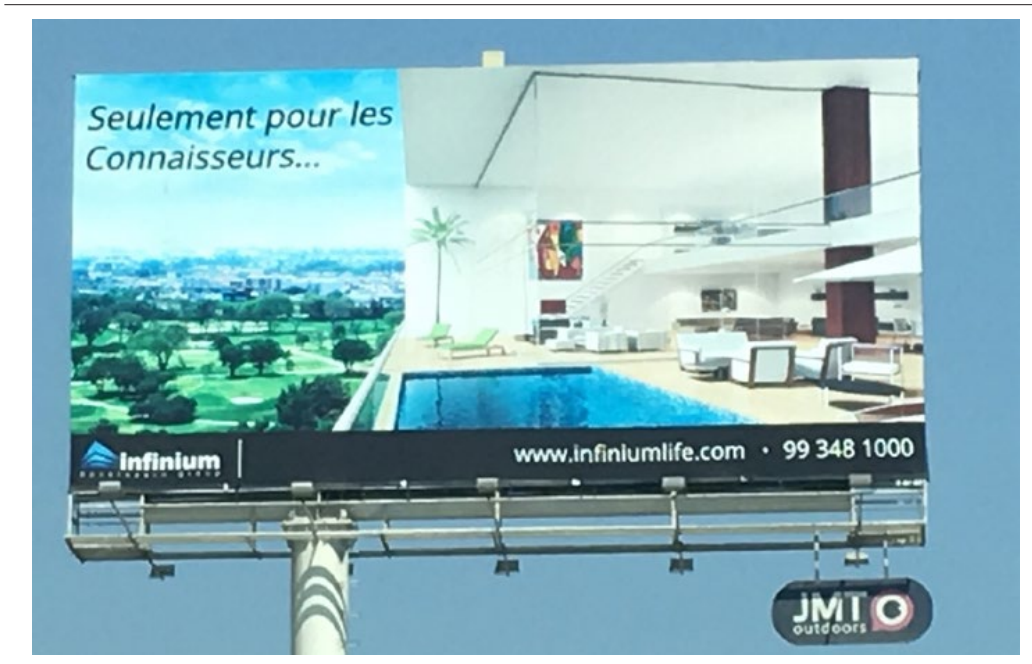

Fuente: Fotografía de Natalí Cárdenas, 2016.

territarias 36

34 experimentando durante el siglo XX. Más bien, parece tratarse de una acentuación de elementos o tendencias que ya se venían vislumbrando bajo la influencia del urbanismo moderno de principios del siglo XX. Por otra parte, si bien no nos hemos detenido mucho, tampoco tenemos elementos de juicio para suponer que en la época colonial o de inicios de la república sí existiese un espacio público adecuadamente definido: ensayos como el de Lima la horrible de Salazar Bondy en 1964 nos advierten que existe una cierta idealización del pasado colonial de la ciudad que es más una construcción ideológica que la referencia a una realidad empírica (2014). Estamos, pues, ante una ciudad, como otras en América Latina, que se erige sobre la base de una naturaleza híbrida, como señala Ciccolella, donde las formas de desigualdad que se expresarían en el espacio público acumulan y yuxtaponen rasgos de diferentes etapas históricas hasta las transformaciones recientes (2011, p.112).

El espacio público, entendido como el espacio social moderno donde puede ocurrir el libre acceso y la pluralidad de acciones, no ha sido un espacio social importante en la urbanización de Lima durante el siglo XX. Esta tendencia se ha agudizado a inicios del siglo XXI y, en términos de la forma en que está creciendo la ciudad, se puede convertir en un serio problema para la vida futura en la ciudad. Lima ha iniciado un proceso de densificación, donde la vida debe proyectarse a partir de departamentos que mayoritariamente son de dimensiones relativamente reducidas y 
donde la constante congestión vehicular está demostrando la ineficacia de la actual política urbana que prioriza la ampliación de vías, construcción de viaductos o pasos a desnivel. Si caminar y usar las calles no forma parte de nuestro proyecto urbano personal, ¿Qué calidad de vida podemos esperar ocupando intensamente espacios privados reducidos o saliendo a destinos alejados para los cuáles solo el viaje motorizado - público o privado- demanda invertir mucho tiempo y energía? Sin embargo, la percepción de la población no hace visible la pobreza de espacios públicos como un problema, adaptándose a su precariedad más como un superviviente que como un ciudadano de Lima.

\section{El transeúnte y los espacios públicos de circulación}

Un hecho llamativo en Lima es el tratamiento de los espacios de tránsito para los peatones. En la medida que las calles de la ciudad son entendidas y tratadas como vías de circulación, la atención prestada a los espacios peatonales es pobre. Las veredas de las calles no superan los dos metro de ancho y en las avenidas es difícil encontrar casos con secciones de vereda mayores a los tres metros.

También es notable la poca atención puesta al mobiliario urbano y a la señalización peatonal. En el primer caso, se pueden encontrar numerosas calles con veredas angostas pero donde inclusive se colocan postes de alumbrado que la hacen incluso más estrecha. Del mismo modo, en áreas de expansión de la ciudad es usual encontrar escaleras exteriores que terminan sobre las aceras. En lo referido a la señalización, es interesante observar cómo el diseño de los pasos peatonales suele ser colocado en las esquinas de las calles sin prestar atención a si estos conectan adecuadamente una acera con otra; el resultado desemboca en situaciones que lindan con lo cómico, donde el peatón no tiene formalmente alternativas reales y seguras de cruzar una calzada. A modo de ejemplo se puede observar cómo el boletín de una gestión municipal como la del distrito de Jesús María, con predominancia de residentes de clase media, muestra con orgullo sus nuevas obras, sin considerar ni darse cuenta que los cruces peatonales - O pasos de cebra- que acaban de diseñar no se conectan adecuadamente con las aceras (figura 4).

Un caso dramático es el de la habilitación de puentes peatonales en avenidas arteriales de la ciudad, donde el principio es que los peatones no interfieran en la circulación vehicular. La forma en que se diseñan y construyen demuestra el poco interés prestado a las necesidades plurales que los transeúntes tienen como personas. Como señalan Dextre \& Avellaneda (2014) la habilitación de puentes debería ser el último recurso en el diseño de la movilidad de una ciudad. El desinterés por el ciudadano de a pie es coherente con una manera de producir la ciudad, donde la atención es puesta casi exclusivamente sobre la circulación de vehículos motorizados y, en particular, de los automóviles de uso privado (figura 5 ). territarias 36

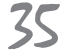


Figura 4: Carátula de boletín de la municipalidad distrital de Jesús María con pasos de cebra mal diseñados

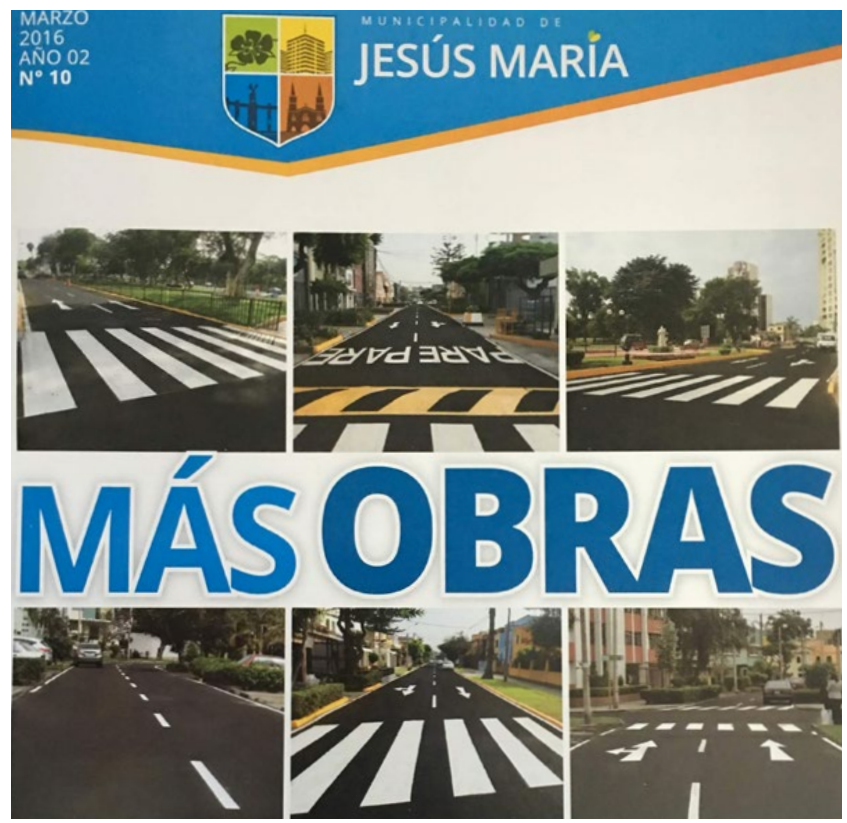

Fuente: Boletín de la Municipalidad de Jesús María Nº10, Marzo 2016.

Figura 5: El peatón debe inventar su paso entre los autos

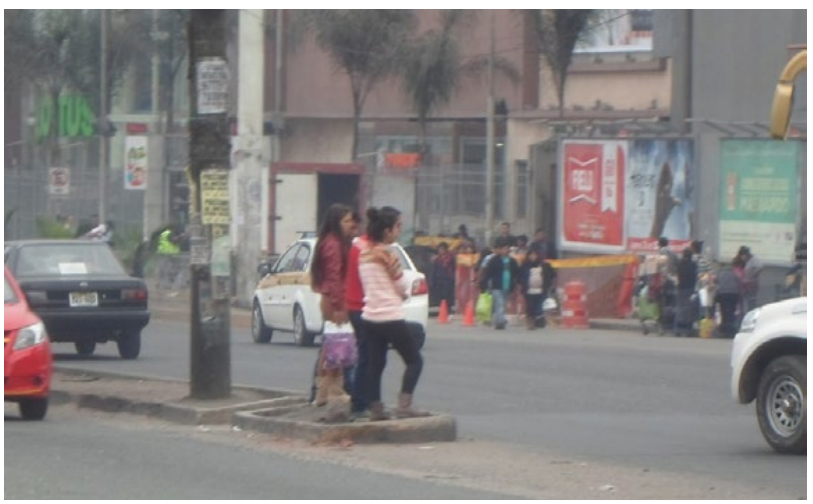

Fuente: Archivo CIAC.

territarias 36

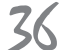

Una consecuencia es la forma en que el peatón debe aprender a experimentar la ciudad. Al salir a caminar, debe habituarse a hacerlo entre veredas angostas o combinar su marcha con la invasión de calzadas. Los cruceros peatonales - muchos mal diseñados como viéramos en la imagen anterior - abundan, pero no son entendidos como reductores de velocidad por los conductores, por lo que los peatones los utilizan solo cuando existen semáforos de por medio o si no se observan vehículos en el momento de cruzar la vía. De otro lado, los puentes peatonales en numerosos casos no son usados por una mezcla de explicaciones como son la excesiva distancia que hay que recorrer hasta llegar a él, las dificultades de tránsito que engloba su propio diseño o la falta de inclusión social que demuestra para ciudadanos con diversidad funcional.

En suma, una ciudad donde las prioridades de la circulación son del vehículo motorizado y los derechos del peatón casi inexistentes, donde el resultado es que éste último realiza comportamientos adecuados a su condición de marginado. Estas prácticas, en muchos casos temerarias e imprudentes, parten de entender que deben subsistir en un territorio que les es ajeno.

El resultado objetivo es que Lima, y en general el país, se han convertido en un territorio hostil para los peatones. Estudios como el de la Organización Mundial de la Salud (OMS) lo confirman, cuando encuentran que el Perú es el país donde el porcentaje de peatones muertos del total de víctimas fatales en accidentes de 
tránsito es la más alta del mundo con un $78 \%$, mientras que en países como Francia y Bélgica no llegan al $15 \%$ y en Chile no supera el $40 \%$ (Vega Centeno et al., 2011, pp. 313-314). Lo curioso es que el propio Ministerio de Transporte, al momento de enfrentar este tipo de problemas, identifica la irresponsabilidad del peatón como una de las causas explicativas en lugar de entenderlo como una consecuencia de la organización de los espacios de circulación (Alegre, 2010).

Como respuesta, y con el apoyo de medios de comunicación masiva que identificaron rápidamente al "mal peatón" como uno de los responsables de los accidentes de tránsito, desde el año 2010 se han comenzado a implementar multas para peatones, medida que no ha tenido mayores efectos en reducir los accidentes fatales, pero sí ha incidido en la manera de jerarquizar los derechos ciudadanos en los espacios de circulación. El peatón se convierte, como lo hemos señalado en algún otro trabajo, en una categoría de marginal urbano (Vega Centeno, 2015).

Caminar por las calles de Lima no es pues una experiencia placentera. En cambio, es un escenario donde el peatón aprende cotidianamente que el usuario con más poder es el conductor de vehículos y que el espacio de la ciudad está a su servicio ${ }^{2}$. La paradoja es que esta situación conflictiva no genera rebelión entre la población marginada sino que se tiende más bien a la aceptación y/o adaptación por fuerza de la costumbre, tal vez con el secreto anhelo de contar con un coche y pasar así del lado de los subordinados hacia el de los que detentan el poder.

Por ejemplo, ante la pregunta formulada en la encuesta de Lima Cómo Vamos el año 2013 sobre qué debe atender prioritariamente la municipalidad entre más y mejores veredas o avenidas más anchas y rápidas para la circulación, el $52.9 \%$ se inclinó por la segunda opción contra un 44.9\% que sí otorgó preferencia a las veredas (Lima Cómo Vamos, 2013).

\section{La ciudad de los residentes o vecinos}

Como señalamos anteriormente, la práctica de enrejar accesos a urbanizaciones no se detuvo con el fin de los atentados terroristas, sino que se incrementó (Plöger, 2006). Esta vez el argumento de la seguridad aludía al peligro de robos y asaltos que efectivamente podían ocurrir en las viviendas por la libertad de movimiento que tienen los desconocidos por las calles de zonas residenciales. Lo que llamará la atención es que este fenómeno se difundirá en diferentes sectores sociales de la ciudad, inclusive en zonas que originalmente fueron barrios populares producto de invasiones. El hecho común al conjunto de lugares que adoptan esta práctica es que se trata de urbanizaciones con predominio casi absoluto del uso residencial. El uso de la calle en estos lugares es principalmente el de facilitar el acceso al que llega o sale de su domicilio. En el conjunto de los casos aludidos, otro hecho común es que ocurre en zonas urbanas que originalmente
${ }^{2}$ Podríamos también agregar el tema de los ruidos, pues la utilización desmedida de las bocinas o cláxones como "medio de comunicación" entre los conductores tiene a los transeuntes como losprincipales perjudicados.

territarias 36

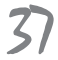


fueron diseñadas integradas al tejido urbano (figura 6); este es el fenómeno que Plöger define - citando a Ludeña- como la proliferación de condominios ex-post y que observa tanto en zonas urbanas de renta alta como en barrios populares de periferia (2006).

En un estudio realizado en la zona sur de Lima, Takano \& Tokeshi (2007, pp. 3132 ) encuentran cómo las propias familias residentes son las que toman la iniciativa de mantener el espacio público. Pero esta iniciativa ocurre en contextos de escala barrial, donde el espacio es entendido como de uso comunal, existiendo una tendencia a privatizar estos espacios públicos. Así, los autores observan que en zonas de origen de barriadas o urbanización popular se ha vuelto una constante el enrejado de calles y parques por iniciativa de comités de gestión de los propios vecinos.

Por otra parte, Sandoval (2013) encontró que, de acuerdo a fuentes de la Asociación Peruana de Consumidores y Usuarios (ASPEC), para el año 2010 existían en Lima 1263 barreras puestas sobre la calle, siendo las rejas la principal modalidad. La paradoja residía, sin embargo, en que de éstas menos del 10\% (116) contaba con los respectivos permisos municipales, fenómeno que ocurre en distritos urbanos tanto de baja como de alta renta. Esto confirma que estamos ante prácticas sociales llevadas a cabo por residentes, al

Figura 6: Urbanización cercada en la zona este de Lima

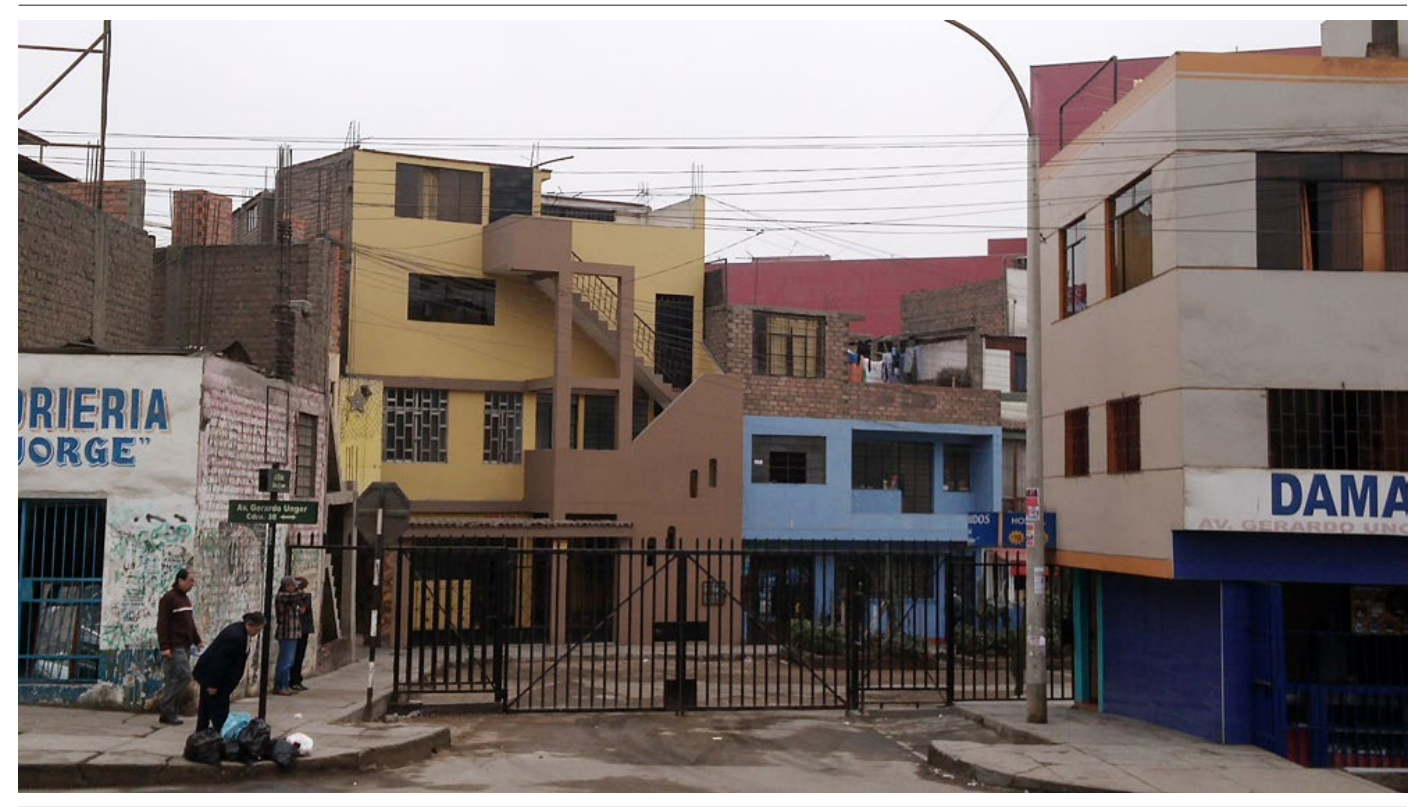

Fuente: Archivo CIAC. 
margen de cualquier política pública. Los residentes o vecinos de una zona de uso predominantemente residencial encuentran legítimo impedir los accesos a las calles y parques de su vecindario a vehículos y peatones extraños a él, a los que mira con desconfianza.

En un sondeo de opinión llevado por el observatorio Lima Cómo Vamos en el año 2013, ante la pregunta de si es legítimo poner cercas o rejas sobre la calle si los residentes de un vecindario se ponen de acuerdo, cerca de la mitad de encuestados manifestó estar de acuerdo, proporción que es inclusive mayor entre las poblaciones de menores ingresos o que residen en zonas de expansión urbana.

Es llamativo el hecho de que la constante marginalización que experimenta el habitante al caminar por las calles de la ciudad no haya sido tomada como reivindicación por algún movimiento social ni sea un gran motivo de debate para la opinión pública. Caminar por la ciudad es una experiencia peligrosa, tanto por el riesgo de ser atropellado como por el poco espacio habilitado para transitar y la probabilidad de ser asaltado. Lo curioso es que, al transitar por la ciudad el peatón al estar fuera de su espacio residencial, se convierte para otros residentes en sujeto potencialmente amenazante. Así como la marginalización y vulnerabilidad del peatón es ignorada, los peligros que éste mismo transeúnte puede suponer para las zonas residenciales de la ciudad sí es materia de preocupación de la opinión pública, bajo el estigma del extraño que puede hacernos daño. Pero, ¿quién es este extraño? ¿cómo lo hemos identificado como tal?

Es en este momento que es preciso poner en relación la manera en que se ha ido expandiendo la ciudad con las formas en que sus habitantes se vienen representando a sí mismos dentro de ella. Un caso significativo es que el habitante de Lima no se identifica como ciudadano, sino como vecino. Puede parecernos una identificación más encarnada al territorio que la primera noción, pero a la vez lo que está suponiendo es situarse en la ciudad partiendo solo del territorio inmediato en el que reside.

La estructura organizativa de la ciudad ayuda a reforzar esta identificación del habitante con su ciudad. El área metropolitana de Lima tiene la particularidad de no contar con una única autoridad municipal. Es administrada por dos gobiernos provinciales, uno para Lima y otro para el Callao, que forma parte del continuo urbano. Pero, además, cuenta en total con 50 gobiernos distritales, los que tienen importante autonomía de gestión con relación a los gobiernos provinciales, pues pueden regular la zonificación y densificación de sus territorios, además de hacerse cargo del mantenimiento de las vías locales. Además, pueden regular y/o restringir los usos de calles y parques de su jurisdicción mediante ordenanzas, muchas veces por petición expresa de sus vecinos.

Esta delimitación administrativa del territorio puede leerse como positiva en términos de acercar la gestión urbana a las demandas cotidianas del habitante. Sin territarias 36 
embargo, cuando esto ocurre en una gran aglomeración urbana resulta inadecuado en varios aspectos, pues la mayor parte de la población distribuye su vida cotidiana en varios lugares de la ciudad; en otras palabras, los habitantes que desarrollan la mayor parte de su vida en torno al espacio residencial son pocos.

Sin embargo, esta forma de gestión urbana es coherente con el tipo de urbanización que fue desarrollándose en la ciudad, como señaláramos anteriormente, donde los espacios tienden a ser de usos homogéneos en las áreas de expansión, tanto en los proyectos inmobiliarios como en la formación de urbanizaciones populares mediante invasiones de terreno.

En consecuencia, la gestión urbana de los distritos atiende las demandas de los que son residentes en su jurisdicción -que además son sus electores-y presta menor atención a aquellos que están de tránsito, salvo que se trate de empresas localizadas en su territorio que den importantes tributos a la alcaldía. De situaciones extremas de este diálogo o acercamiento entre la autoridad municipal y sus electores dan testimonio las cartas o llamadas de vecinos residentes de Miraflores, reclamando a su Alcalde que excluya mendigos, comerciantes ambulantes, jóvenes con patinetas o skates y, en general, a todo aquel que haga "bulla" en espacios públicos próximos a sus residencias y que a su vez estigmatizan como habitantes de zonas periféricas (Bensús, 2012, p. 98).

El habitante-residente aprende que tiene derechos en su entorno residencial y es en ese contexto que es capaz de generar reclamos o inclusive movimientos sociales, tanto en barrios populares como en zonas residenciales de renta media o alta. Cuando existen proyectos inmobiliarios que puedan generar cambios importantes en el distrito o ensanches de vías, inmediatamente surgen reacciones en defensa de la integridad del territorio. Podemos entender estas demandas como una dimensión del ejercicio de derechos ciudadanos pero es importante observar sus límites, pues estas reivindicaciones se sitúan en el marco de una defensa generalizada del carácter residencial que esperan tenga un distrito o parte de esta jurisdicción.

Un ejemplo de ello resultan los Planes de Desarrollo Concertado (PDC), instrumento de planificación vigente según el marco normativo de la gestión urbana en el Perú desde el año 2010. El espíritu de esta norma era buscar una mayor participación de parte de la población en la toma de decisiones de la marcha del territorio en que viven. La gran limitación es justamente que los residentes de un territorio "viven" buena parte de su vida cotidiana fuera de su espacio residencial. Y viceversa, numerosos habitantes no residentes sí "viven" o permanecen en territorios ajenos a su vivienda más tiempo que los propios residentes de ésta. En otras palabras: la ley permite la participación en los PDC a los residentes de un distrito, pero ello no da voz ni voto a quienes permanecen buena parte de vida cotidiana en este lugar o transitan por ahí. Un resultado significativo al respecto es el reciente Plan de Desarrollo del distrito 
de San Isidro, que es reconocido como el principal nodo financiero del país, pero que al momento de definir su visión reivindica antes que nada su carácter residencial pues se define como: "Distrito residencial, comunidad internacional, tradicional, cultural y moderno" (Plan Urbano Distrital de San Isidro 2012-2022).

Por su residencialidad, los vecinos esperan una jurisdicción con poco flujo de personas, donde la presencia de extraños se vea restringida al uso de aceras de algunas vías arteriales, pues estos son considerados como un posible peligro para su tranquilidad cotidiana. Esta suerte de imposición de los intereses del vecino-residente que termina excluyendo de su entorno al transeúnte no-residente es un fenómeno que se viene agudizando en las últimas décadas.

En las representaciones de los residentes de sectores sociales de nivel socioeconómico medio o medio alto, el peligro del otro se mezcla con una aversión a la presencia de habitantes de sectores sociales diversos. En varios testimonios el miedo al extraño se expresa en el habitante pobre "residente de barrios populares o barriadas". Bajo esta premisa, inclusive iniciativas que busquen mejorar el espacio público de sus entornos pueden ser vistas como una amenaza, debido a que "va atraer a gente de barriadas" 3 . En este caso, se aplica muy bien la noción de "agorafobia" utilizada por Jordi Borja (2003, p. 211), pues estamos ante una clara enfermedad de clase, de miedo o aversión a la diversidad social.

Sin embargo, este tipo de representaciones no se limita a un sector social de la ciudad, pues residentes de barrios populares también ponen en práctica este tipo de iniciativas de exclusión. Como señaláramos anteriormente, son numerosos los barrios populares que han realizado intervenciones que excluyen o segregan el acceso de extraños a sus respectivas urbanizaciones pues, como señalan Takano \& Tokeshi, se perciben las áreas libres del barrio como espacios comunales, mas no públicos. En este caso, la "agorafobia" no sería un argumento suficiente, pues la noción de espacio público es pobre. ¿Cómo tener miedo al espacio público si este no es visible en la percepción cotidiana?

En cambio, resulta útil una noción como la propuesta por De Certeau \& Mayol al definir la noción de barrio, cuando afirman que "debe entenderse como esa porción del espacio público en general donde se insinúa poco a poco el espacio privado particularizado" (1999, p.8). En efecto, los entornos residenciales son percibidos como un conjunto de áreas comunes donde los protagonistas son quienes tienen su vivienda en dicho espacio y se reconocen como vecinos. Se trata de una lógica de apropiación territorial donde se entiende que los residentes, que utilizan cotidianamente esos espacios, son también responsables de su cuidado y, por ende, tienen la potestad de poner reglas de comportamiento en él e inclusive de restringir su acceso.

En los tejidos urbanos no suele haber una clara delimitación entre los espacios dominados por vecinos con relación a aquellos donde los transeúntes son los
${ }^{3}$ En concreto, este fue uno de los principales argumentos que residentes del distrito de San Borja, que concentra principalmente población de clase media, expusieron para oponerse a proyectos de micro-intervención en espacio público que estudiantes de arquitectura de la PUCP diseñaron y montaron con el apoyo de la Municipalidad del Distrito el año 2015, reemplazando estacionamientospor mobiliario de descanso para transeuntes. territarias 36

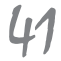


usuarios mayoritarios. Forma parte de la vida urbana de una ciudad, donde el investigador urbano debe aproximarse a las dinámicas cotidianas para entender cómo operan estos actores. Y el análisis se vuelve más complejo cuando se observa que en muchos espacios de carácter residencial, es posible identificar que sus principales personajes son habitantes no-residentes, que ocupan el espacio con relativa permanencia por motivos laborales como son panaderos, limpiadores de carros, guardianes, canillitas, etc.

\section{Las múltiples facetas urbanas de la desigualdad social}

La desigualdad en una sociedad se expresa en los accesos inequitativos a las diferentes oportunidades que pueden permitirnos un desarrollo humano pleno. En una mirada urbanística, la búsqueda de disminuir las brechas de desigualdad entre los habitantes de una ciudad debe estar dirigida a ofrecer oportunidades semejantes para el acceso a servicios y equipamientos en los cuales la vida urbana satisface necesidades como la vivienda, la alimentación, el trabajo, el estudio o la recreación.

Lo que sin embargo tendemos a olvidar es que en la propia experiencia de trasladarse para acceder a estos numerosos motivos que hacen la vida en una ciudad, los habitantes también experimentan condiciones de desigualdad. El acceso a estas oportunidades nos sitúa dentro de la ciudad en el marco de lógicas de movilidad espacial que cristalizamos en lo que urba- nísticamente son los espacios públicos de la ciudad, y que jurídicamente son aquellos en donde sus usuarios son considerados $\mathrm{co}^{-}$ mo iguales. Es en esta dimensión cotidiana de desplazarnos de nuestros hogares hacia los múltiples destinos que ocupan nuestra vida social que nos confrontamos a diferentes dimensiones de desigualdad social, que ponen en evidencia situaciones conflictivas entre nuestros marcos normativos como sociedad y la propia organización y gestión de la ciudad.

Una primera dimensión de esa desigualdad es la funcionalización de los espacios públicos, acción urbanística por la que se identifican las calles como vías de circulación y los parques como áreas recreativas. En el primer caso, la prioridad absoluta otorgada al auto privado y en general a los medios de transporte motorizado por encima de ciclistas y sobre todo de transeúntes, convierte a estos últimos en los usuarios más vulnerables de las calles de la ciudad, los que sin embargo, como se indicó anteriormente, pueden ser inclusive vistos como uno de los principales responsables de los accidentes de tránsito y por ende merecedores de sanciones punitivas.

Una segunda dimensión de esta desigualdad está dada por las restricciones que muchos vecindarios imponen sobre calles y parques que forman parte de su entorno residencial. El habitante de la ciudad no residente encuentra que en numerosas zonas de la ciudad tendrá el acceso limitado para circular ante el alto número de rejas y cercas que impiden el paso por muchas calles de la ciudad. Esta situación 
se agudiza con el tratamiento que recibe el transeúnte, al que se le impide el derecho a la recreación en parques públicos de zonas residenciales ajenas a la suya, y es continuamente vigilado, controlado y hasta expulsado por sistemas de seguridad privados o municipales de dichas zonas residenciales.

Una tercera dimensión de estas experiencias cotidianas de desigual acceso a los espacios públicos está dada por el actual sistema de gobierno municipal, con 50 distritos democráticamente elegidos por sus residentes y que entienden que su política debe atender prioritariamente las demandas de sus electores. Este razonamiento, que en principio resultaría legítimo, ocurre en jurisdicciones que no son autónomas, sino que forman parte del extenso continuo urbano de la metrópoli, donde la mayoría de electores ocupan este espacio parcialmente, pues su vida cotidiana los conecta diariamente con otros lugares de la urbe. El resultado es que tenemos municipios donde es usual que el vecino residente se sienta con derechos superiores a cualquier transeúnte que no lo sea y es capaz de ejercer presión sobre sus gobiernos municipales a fin de que controle, segregue e inclusive expulse a aquellas personas que identifique o perciba como peligrosas para su seguridad o tranquilidad personal y de su familia.

Estas dimensiones urbanas de la desigualdad social ya existían antes de que el proceso de reestructuración metropolitana, como consecuencia de la economía global y el retorno de la inversión inmobiliaria, ocurriese a fines del siglo XX. No podemos afirmar, entonces, que fueran las políticas neoliberales o los nuevos productos inmobiliarios los responsables de segregar o eliminar los espacios públicos urbanos. Lo que en cambio sí podemos señalar es que las estrategias de venta de la oferta de nuevos espacios residenciales refuerzan el "miedo a la calle" y reafirman una visión donde la calidad de vida de las familias parece concentrarse en el uso intensivo del nuevo hogar bajo la modalidad de condominio y los espacios de recreación y esparcimiento fuera de la residencia pueden ser satisfechos en productos inmobiliarios como los malls.

El diseño urbano de la ciudad, las inserciones urbanas de los proyectos inmobiliarios, las políticas municipales y las prácticas sociales de los vecinos, coinciden en marginar al extraño que camina por las calles como sujeto estigmatizable, peligroso para la tranquilidad pública y por el cual la gestión urbana debe vigilar o controlar sus movimientos. Y cuando se legitiman estas prácticas, se hace evidente que la condición de peatón sospechoso se superpone con otras características sociales, como pueden ser signos exteriores de pobreza, juventud $\mathrm{o}$ inclusive criterios raciales.

En efecto, en una ciudad como Lima el crecimiento económico ha supuesto el incremento del empleo, pero principalmente el de carácter precario, no sujeto a estabilidad laboral ni a otros beneficios sociales y en muchos casos de carácter informal que diariamente se traslada desde distintas zonas periféricas de la ciudad a territarias 36

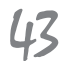


los distritos localizados en el área central, que concentran la mayor cantidad de empleo en la ciudad, como mencionáramos al inicio de este artículo.

La organización del empleo ya expresa una situación de desigualdad social, pero esta puede reforzarse o agudizarse cuando observamos la experiencia urbana de ir cotidianamente a trabajar a estos lugares, donde los entornos residenciales se preocuparán constantemente por hostilizar a todo aquel que no sea residente o reúna características físicas o sociales que lo identifiquen como "peligroso".

En síntesis, el habitante que camina en Lima experimenta la ciudad no como ciudadano, con derechos y deberes, sino como residente cuando está en torno a su hogar, donde asume con seguridad la potestad de reclamar ante sus autoridades ediles la gestión de su territorio. Pero también la experimenta como transeúnte no-residente, donde aprende a diario que la ciudad le es ajena y hostil porque pertenece a "otros residentes". Y a ello debe agregar su condición de usuario segregado la calle como espacio vial, donde todo vehículo motorizado tendrá prioridad de paso sobre él. Lo paradójico es que como habitantes de la ciudad, no hacemos visible nuestra condición de peatón no-residente en nuestras percepciones ni reclamos.

Este es el actual grado de fragmentación que vive Lima no solo como espacio producido, sino en los usos y representaciones que sus propios habitantes hacen de ella, fenómeno de desigualdad social que es posible observar con toda su crudeza en el uso cotidiano de los espacios públicos de la ciudad.

\section{Referencias}

Alegre, M. (2010). Todos somos peatones: un enfoque de derechos para el tratamiento de la movilidad urbana en Lima Metropolitana. Lima: Tesis de Magíster en Derechos Humanos, PUCP.

Arellano, R. (2010). Ciudad de los Reyes, de los Chávez, de los Quispe. Lima: El Comercio.

Ascher, F. (2004). Los nuevos principios del urbanismo. Madrid: Alianza Editorial

Bensús, V. (2012). La ideología de la inseguridad y segregación en el espacio público de Lima Metropolitana: el caso de la gestión 2007-2010 en Miraflores. Revista Debates en Sociologia, (37), 77108.

Boano, C. \& Desmaison, B. (11 de febrero de 2016). Lima's 'Wall of Shame' and the gated communities that build poverty into Peru. The conversation. Recuperado de https://theconversation. com/limas-wall-of-shame-and-the-gated-communities-that-build-povertyinto-peru-53356

Borja, J. (2003). La ciudad conquistada. Madrid: Alianza editorial

Caldeira, T. (2007). Ciudad de Muros. Barcelona: Ed. Gedisa.

Calderón, J. (1990). Las ideas urbanas en el Perú: 1958-1989. Lima: CENCA.

Calderón, J. (2014). Miradas, enfoques y estudios sobre las ciudades. Lima: Ed. Vicio Perpetuo. 
Carrión, F. (2007). "Espacio público: punto de partida para la alteridad". En Segovia, O. (Ed.). Espacios públicos y construcción social: hacia un ejercicio de ciudadanía, (79-85). Santiago de Chile: Ed. Sur.

Castells, M. (1997). La Sociedad Red. Volumen 1: La era de la información. Madrid: Alianza Editorial.

Chion, M. \& Ludeña, W. (2005) "Espacios públicos, centralidad y democracia. El centro histórico de Lima periodo 19802004". Revista URBES, (2), 145-169.

Ciccolella, P. (2011). "Metrópolis latinoamericanas: ‘territorios subregulados, espacios del capital?”. En Ciccolella, P. (Comp.) Metrópolis latinoamericanas. Más allá de la globalización. Buenos Aires: Ed. Café de las Ciudades - OLACCHI.

De Certeau, M. \& Mayol, P. (1999). La invención de lo cotidiano. Volumen 2. México: Universidad Iberoamericana.

De Mattos, C. (2008). "Globalización, negocios inmobiliarios y mercantilización del desarrollo urbano". En P. Pereyra, \& R. Hidalgo (Ed.). Producción inmobiliaria y reestructuración metropolitana en América Latina. (23-40). Santiago: PUCCH-USP.

Delgado, M. (1999). El animal público. Hacia una antropología de los espacios urbanos. Barcelona: Ed. Anagrama

Delgado, M. (2007). Sociedades Movedizas. Pasos hacia una antropología de las calles. Barcelona: Ed. Anagrama.
Dextre, J. \& Avellaneda, P. (2014). Movilidad en zonas urbanas. Lima: PUCPFundación Transitemos.

Duhau, E. \& Giglia, A. (2008). Las reglas del desorden habitar la metrópoli. México: Universidad Autónoma Metropolitana.

Gonzales, E. \& Del Pozo, J. (2012). "Lima, una ciudad policéntrica. Un análisis a partir de la localización del empleo". Revista Investigaciones Regionales, 23, 29-52.

Habermas, J. (1991). The Structural transformation of the public sphere. Cambridge: MIT Press.

Joseph, I. (1988) El transeúnte y el espacio urbano: ensayo sobre la dispersión del espacio público. Barcelona: Gedisa.

Kostof, S. (2000). The city assembled. Londres: Thames \& Hudson.

Le Corbusier. (1959). Cómo concebir el urbanismo. Buenos Aires: Ed. Infinito.

Lefebvre, H. (2014). La producción del espacio urbano. Madrid: Capitán Swing.

Ludeña, W. (2002) "Lima, poder, centro y centralidad". Revista EURE, 83, 45-65.

Lima Cómo Vamos, Observatorio Ciudadano (2013). Encuesta Lima Cómo Vamos 2013.

Lima Cómo Vamos, Observatorio Ciudadano (2015). Encuesta Lima Cómo Vamos 2015. Quinto informe de percepción sobre calidad de vida.

Municipalidad de San Isidro (2012). Plan Urbano Distrital de San Isidro 20122022. Lima: Municipalidad de San Isidro. 
Oficina Nacional de Planeamiento y Urbanismo (ONPU) Esquema director 196780. Plan de Desarrollo Metropolitano Lima Callao.. Lima: Oficina Nacional de Planeamiento y Urbanismo.

Panerai, P. \& Mangin, D. (2002). Proyectar la ciudad. Madrid: Ed. Celeste.

Plöger, J. (2006). La formación de enclaves residenciales en Lima en el contexto de la inseguridad. Revista Urbes, (3), 135-164.

Remy, J. \& Voyé, L. (1981). Ville: ordre et violence. Paris: PUF.

Salazar Bondy, S. (2014). Lima la horrible (3. ${ }^{\text {ra }}$ ed.). Lima: Lápix eds.

Salcedo, R. (2002) "El espacio público en el debate actual: una reflexión crítica sobre el urbanismo post-moderno". Revista EURE, 84, 5-19.

Sandoval, G. (2013). Vivir entre rejas: seguridad ciudadana y privatización de la calle en urbanizaciones de Ate y La Molina. Lima: Tesis de magíster en sociología, PUCP.

Sassen, S. (1991). The global city: New York, London, Tokyo. Princeton: Princeton University Press.

Sassen, S. (2007). Una sociología de la globalización. Buenos Aires: Kats.

Simmel, G. (1998) "Las grandes ciudades y la vida del espíritu". En Simmel, G., El individuo y la libertad (pp. 247-261). Barcelona: Ediciones Península.
Takano G. \& Tokeshi, J. (2007). El espacio público en la ciudad popular. Lima: DESCO.

Vega Centeno, P. (2004). "De la barriada a la metropolización; Lima y la teoría urbana en la escena contemporánea. En C. Aramburú, et al. Perú Hoy: las ciudades en el Perú. (45-70) Lima: DESCO.

Vega Centeno, P. (2006). El espacio público: la movilidad y la revaloración de la ciudad. Lima: Departamento de Arquitectura de la PUCP.

Vega Centeno, P. (2013). “¿Dónde somos limeños? Explorando los espacios públicos de la ciudad". En C. Aguirre \& A. Panfichi (Eds.). Lima, siglo XX. Cultura, socialización y cambio. (123144). Lima: PUCP.

Vega Centeno, P. (2015). El espacio público y la visión de ciudad: recuperando el valor de la calle para la ciudadanía. En Ledesma, M. (Coord.), Justicia, derecho y sociedad. Debates interdisciplinarios para el análisis de la justicia en el Perú. (351-378). Lima: Tribunal Constitucional del Perú.

Vega Centeno, P., Dextre, J. \& Alegre, M. (2011). Inequidad y fragmentación: movilidad y sistemas de transporte en Lima Metropolitana. En C. De Mattos, L. Ludeña, (Eds.), Lima_Santiago. Reestructuración y cambio metropolitano (pp. 289-328). Lima: CIAC-PUCP. 